Mal J Nutr 26(1): 019-030, 2020

\title{
Understanding barriers towards the use of food labels among Saudi female college students
}

\author{
Al-Barqi R, Al-Salem Y, Mahrous L, Abu Abat E, Al-Quraishi R \& Benajiba N* \\ Clinical Nutrition Programme, Department of Health Sciences, College of Health and \\ Rehabilitation Sciences, Princess Nourah Bint Abdulrahman University, Saudi Arabia
}

\begin{abstract}
Introduction: A food label is an important tool that provides nutritional information which influences consumers by promoting awareness on their diet and improving health status. This study aimed to assess nutrition knowledge level, food label usage, and the barriers that hinder the use of food labels among students in Health Colleges at the Princess Nourah Bint Abdulrahman University (PNU). Methods: A cross-sectional study was conducted among Health College students at PNU in Riyadh (Saudi Arabia). A total of 572 participants were interviewed through a validated questionnaire on social demographic characteristics, nutrition knowledge level, food label use, and barriers that hinder food label use. Statistical analysis was performed using SPSS (version 21), with statistical significance set at $p$-value $<0.05$. Results: Only $27.4 \%$ of the participants stated that they always or usually use food labels when purchasing food products. Majority of the participants (59.4\%) had moderate nutrition knowledge. Factors significantly associated to food label use were nutrition knowledge $\left(R^{2}=0.21\right)$, attitude towards health value of the products $\left(R^{2}=0.35\right)$, and taste $\left(R^{2}=-0.22\right)$. About $41.0 \%$ of the participants indicated that time constraint was the main barrier for not using food labels, followed by no interest $(31.3 \%)$, no need $(27.8 \%)$, and difficult to use $(24.8 \%)$. Conclusion: This study found that food label use was low among the participants. Nutrition knowledge supported food label use while time constraint was the main barrier that hindered the use of food label among them. Raising students' nutrition knowledge level through nutrition education programmes could promote food label use.
\end{abstract}

Keywords: Food label use, female university students, barriers, Saudi Arabia

\section{INTRODUCTION}

A balanced diet plays a significant role in promoting health and preventing both overnutrition and undernutritionrelated diseases, such as obesity, type II diabetes mellitus, hypertension, and micronutrient deficiencies. According to Saudi Health Interview Survey (SHIS) (IHMS, 2013), such diseases are considered as major public health problems among the Saudi population. Furthermore, a more recent report by the
World Health Organization (WHO) (2018) indicated that $73 \%$ of all deaths in Saudi Arabia are related to non-communicable diseases. In addition, a 7-year metaanalysis study revealed that $63 \%$ of the Saudi population suffer from vitamin D deficiency (Al-Alyani et al., 2018), while Al-Assaf (2007) demonstrated that iron deficiency anaemia is highly prevalent among adult Saudi women in Riyadh as $95.1 \%$ of this population have lower iron intake than the Dietary Reference Intake

\footnotetext{
*Corresponding author: Dr. Nada Benajiba Address: College of Health and Rehabilitation Sciences, Princess Nourah Bint Abdulrahman University P.O. Box 84428, Riyadh 11671, Kingdom of Saudi Arabia Tel: +966(1)18240752; E-mail: benajibanada@gmail.com doi: https://doi.org/10.31246/mjn-2019-0117
} 
(DRI) recommendation. In response to this situation, policies and regulations have been put in place by the Saudi government in an attempt to combat nutrition-related health problems (Mokdad, 2016). With this regard and in line with Saudi Arabia's vision 2030, the Saudi Food \& Drug Authority (SFDA) recently set up a strategy to regulate healthy dietary habits through reduction of sugar, salt, saturated, and trans fats in products (SFDA, 2018a), reinforcing the mandatory pre-packed food labelling that was implemented since 2007 (Al-Kandari \& Jukes, 2009). In fact, the SFDA is the institution that oversees all matters related to foods including food laws and regulations, information and education activities for the consumers (Al-Kandari \& Jukes, 2012). Saudi Arabia has officially adopted new standards for food labelling on pre-packed foods, as set by the Gulf Cooperation Council's Standardization Organization (GSO) (GSO9/2007), thus bringing the Gulf Cooperation Council's standards into closer compliance with the Codex Alimentarius guidelines. After that, in 2012, Saudi Arabia enforced the Gulf Cooperation Council's regulations concerning the disclosure of nutrition information on food labels (GSO 2233/2012), which was issued in the same year. Labelling requirements include nutritional information such as calorie counts, carbohydrates, proteins, fats, and other components that may affect the product's nutritional value or consumers' health or safety, and requirements for production and expiration dates (Al-Kandari \& Jukes, 2009).

The aim of food labels is to provide dietary guidelines to the consumers and promote awareness of their eating habits, food quality, and daily food requirements (FDA, 2018). According to Lewis et al. (2009), increasing the use of food labels might improve health status and prevent nutrition-related problems. A recent systematic review that is based on self-reporting of food label use confirmed the positive effects on consumers' dietary intake; reflected in the reduction of energy intake by $6.6 \%$, total fat intake by $10.6 \%$, other unhealthy foods by $13.0 \%$. This strengthens the fact that food label is a way to influence consumers' purchasing decisions and ability to differentiate between healthy and unhealthy foods (Anastasiou, Miller \& Dickinson, 2019). However, food labelling can only be effective if used properly and frequently by consumers. Miller and Cassady (2015) showed that the more nutrition knowledge consumers have, the more likely they are able to understand and use food labels to guide them towards making healthy decisions. However, there are barriers to the proper use of food labels that include shortage of time, difficulty to use, or no interest (Samson, 2012; Kristal et al., 1998). Although food labelling and disclosure of nutrition information on food labels are mandatory in Saudi Arabia since 2007, few studies have been conducted on the use of food labels by Saudi consumers. Previous studies placed emphasis on special foods such as genetically modified food (Bakr \& Ayinde, 2013), or on a specific ingredient such as hydrogenated oil (Kamel \& Al Otaibi, 2018), or additives (Sachithananthan, 2017). In 2001, a research by Washi showed that the majority of Saudi consumers lacked knowledge in relation to the information on food labels such as nutritional content, serving size, and health claims. A pilot survey conducted among University students in Riyadh, Saudi Arabia to assess the importance and regular use of food labels showed that although $98 \%$ of responders confirmed the importance of food label, only $20 \%$ of them used it daily (unpublished data).

Overall, due to the gap in the existing literature related to how effective is the use of food label among Saudi consumers, the aim of this study was to assess the frequency of food label use among female students in Health Colleges at Princess 
Nourah Bint Abdulrahman University (PNU) (Riyadh). Nutrition knowledge as a promoting factor and barriers hindering the use of food labels was also investigated in order to gain better understanding relating to food label use among this population. This will be useful in exploring whether efforts made at the institutional level (SFDA) through policies and regulations related to food labelling have been transcended and translated in terms of behaviour among Saudi consumers through frequent and effective use of food labels. Thus, emphasis will be made on elaborating appropriate recommendations to meet the expected effects of food labelling regulations on the health of the Saudi population.

\section{MATERIALS AND METHODS}

\section{Study design and respondents}

A cross-sectional study was carried out among Health College female students at PNU (Riyadh, Saudi Arabia), from January to March 2019, in which a total of 572 students participated. They were split among five Health Colleges based on convenient stratified sampling as follows: 159 students from the Health and Rehabilitation Sciences College, 141 students from the College of Nursing, 131 students from the College of Pharmacy, 89 students from the College of Medicine, and 52 students from the College of Dentistry.

Students having any health conditions such as a chronic diseases, food allergies, or micronutrient deficiencies, or who were following a weight loss/gain diet, or a diet to treat a medical condition were excluded from the study, because they would have most likely been using the food label.

The study was carried out after obtaining ethical approval from the Institutional Review Board committee of PNU (IRB Approval Number H-01-R-059/180365). Before taking part in the study, all participants were provided with a consent form about the purpose of the study and their role in the study. The participation was voluntary, and the respondents had the option to refuse taking part in the study. There were no physical or psychological risks involved by taking part in this study. Furthermore, there were no direct benefits to the participants. All data collected from the participants were kept confidential.

\section{Research tools}

A valid questionnaire was used to collect data. It consisted of four sections.

\section{Section 1}

It included sociodemographic characteristics of participants such as age, specialty field, marital status, place of living and the responsibility of food purchasing.

\section{Section 2}

This section aimed to measure the nutrition knowledge of the participants. It contained multiple-choice questions with only one correct answer and was used to test the respondents' knowledge on the basic concepts of nutrition. The questions were adapted from the General Nutrition Knowledge Questionnaire (GNKQ) (Kliemann et al., 2016). A 30-point score was used to evaluate the respondents' nutrition knowledge and based on the points scored, respondents were grouped into the following categories: scores of $0-10$; 11-20; 21-30 points, indicative of low, moderate and high nutrition knowledge level respectively (Kliemann et al., 2016).

\section{Section 3}

Questions in this section were related to the frequency of using the food label and nutrition information on food packages during purchasing. Questions were adapted from the Food and Drug Administration (FDA) Health and Diet Survey (FDA, 2014) and a study by Williams (2011). Frequency categories 
Table 1. Sociodemographic characteristic, frequency of food label use and nutrition knowledge scoring of the studied population $(n=572)$ [presented as $\%$ of total population $(n=572)$, except for age as mean $\pm S D]$

\begin{tabular}{lcc}
\hline Variables & $\%$ & mean \pm SD \\
\hline Age (years) & & \\
Specialty & 27.8 \\
Health and rehabilitation & 15.6 \\
Medicine & 24.7 \\
Nursing & 9.1 \\
Dentistry & 22.9 \\
Pharmacy & \\
Marital status & 94.8 \\
Single & 3.8 \\
Married & 1.4 \\
Other & \\
Living with & 91.8 \\
Family & 8.2 \\
Alone in the university dormitory & \\
Person responsible for food purchase at home & 24.5 \\
Myself & 68.5 \\
Parents/relatives & 7.0 \\
Maid/driver & \\
Frequency of food label & 17.7 \\
Never & 16.8 \\
Rarely & 38.1 \\
Sometimes & 17.8 \\
Usually & 9.6 \\
Always & \\
Nutrition knowledge scoring & 17.0 \\
Low & 59.4 \\
Moderate & 23.6 \\
High &
\end{tabular}

were never, sometimes, often, usually, and always. Then, on a 5-point Likert scale (Likert, 1932), (1=not important, 2=slightly important, 3=neutral, 4=important, $5=$ very important or $1=$ strongly disagree, $2=$ disagree, $3=$ neutral, $4=$ =agree and $5=$ strongly agree), participants were requested to answer questions related to their attitudes towards the importance of price, health value, and taste during food purchasing, and the purchasing of unhealthy foods even after reading food labels.

\section{Section 4}

This last section focused on barriers that hinder food label use. Questions in this section were adapted from the FDA Health and Diet Survey (FDA, 2014). The barriers covered the main reasons for not using the food labels; which were lack of time, difficulties encountered when using the food labels, no need to read food labels, and no interest in using food labels. In addition, participants who confirmed that food labels were difficult to use, or they do not need to use food labels were requested to further answer detailed questions related to these aspects. All answers were made on a 5-point Likert scale (1=strongly disagree, $2=$ disagree, $3=$ neutral, 4=agree and $5=$ strongly agree) (Likert, 1932). 


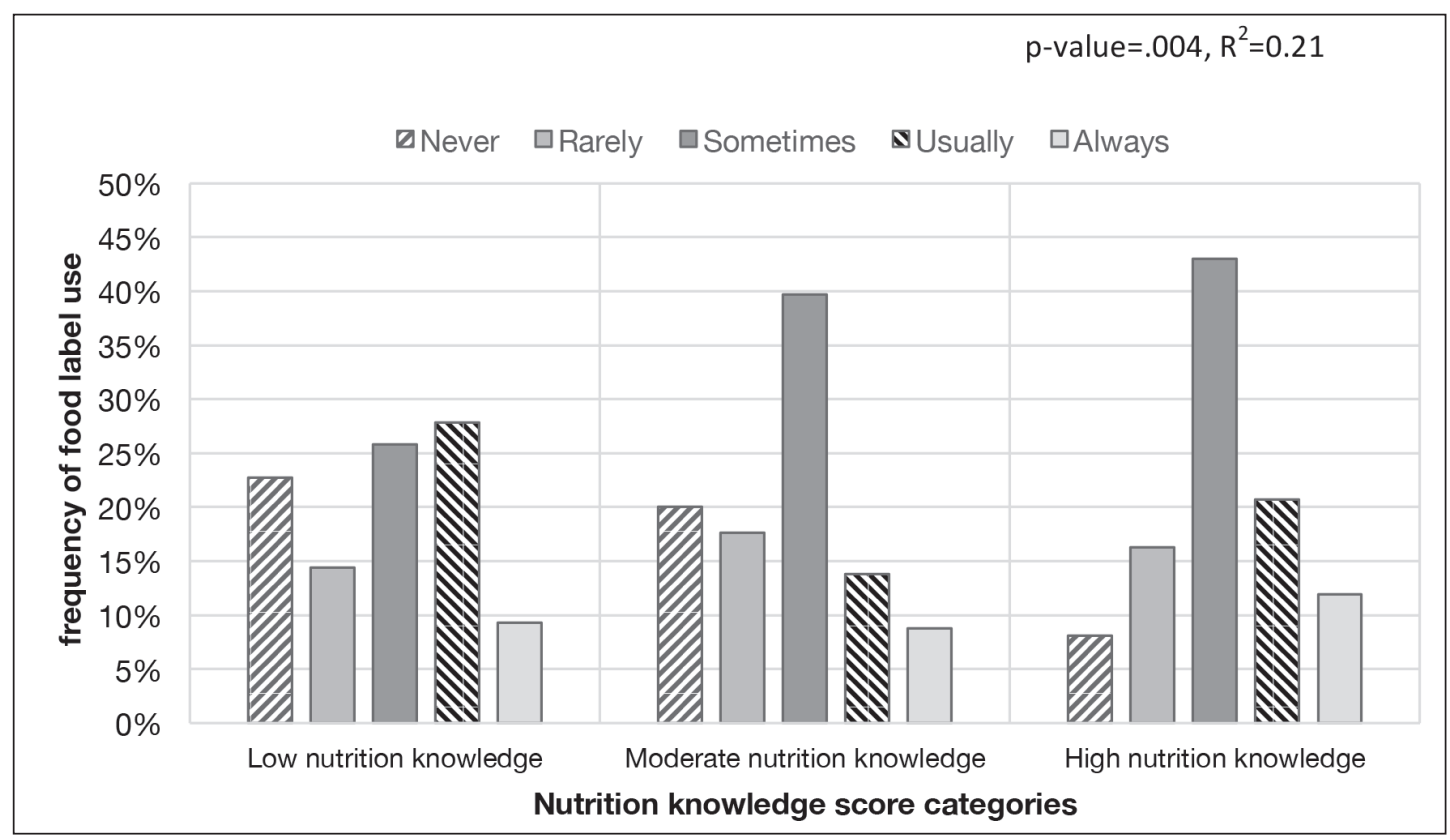

Figure 1. Frequency of food labels use according to nutritional knowledge of participants. Results are presented in percentage for each nutrition knowledge score categories

\section{Reliability and validity of the questionnaire}

The English language was used in the questionnaire, as Health College students were capable of understanding English. The questionnaire was pretested among 20 female students in order to guarantee its ease of understanding by the respondents. Minor modifications were made before its distribution. Reliability of the questionnaire was checked by Cronbach's alpha and this was equal to 0.76 in all sections, with a $95 \%$ confidence interval. The validity of the nutrition knowledge questions was confirmed by Pearson's correlation coefficient $>0.3$ for all questions.

\section{Statistical analysis}

Data was analysed by IBM SPSS statistics software version 21. Results were presented as percentage or mean \pm standard deviation (SD). Spearman's test was used to evaluate the correlation between categorical variables (frequency of food label use versus attitudes); while logistic regression was performed to assess the correlation between categorical and continuous variables (frequency of food label use versus scoring of nutrition knowledge). Statistical significance level was set at $p$-value $<0.05$.

\section{RESULTS}

\section{Sociodemographic characteristics, food label use and nutrition knowledge}

Table 1 summarises the sociodemographic characteristics of participants and frequency of food label use $(n=572)$. The majority of participants were single $(95.0 \%)$ and only $8.2 \%$ lived alone in a university dorm. The majority $(68.5 \%)$ of participants reported that their parents were responsible for food purchasing. The frequency of food label use as stated by participants was $17.7 \%$ and $16.8 \%$ for never and rarely, respectively, while only $9.6 \%$ of the participants reported always using food labels. The majority of participants (59.4\%) had moderate knowledge about general nutrition (Table 
Al-Barqi R, Al-Salem Y, Mahrous L et al.

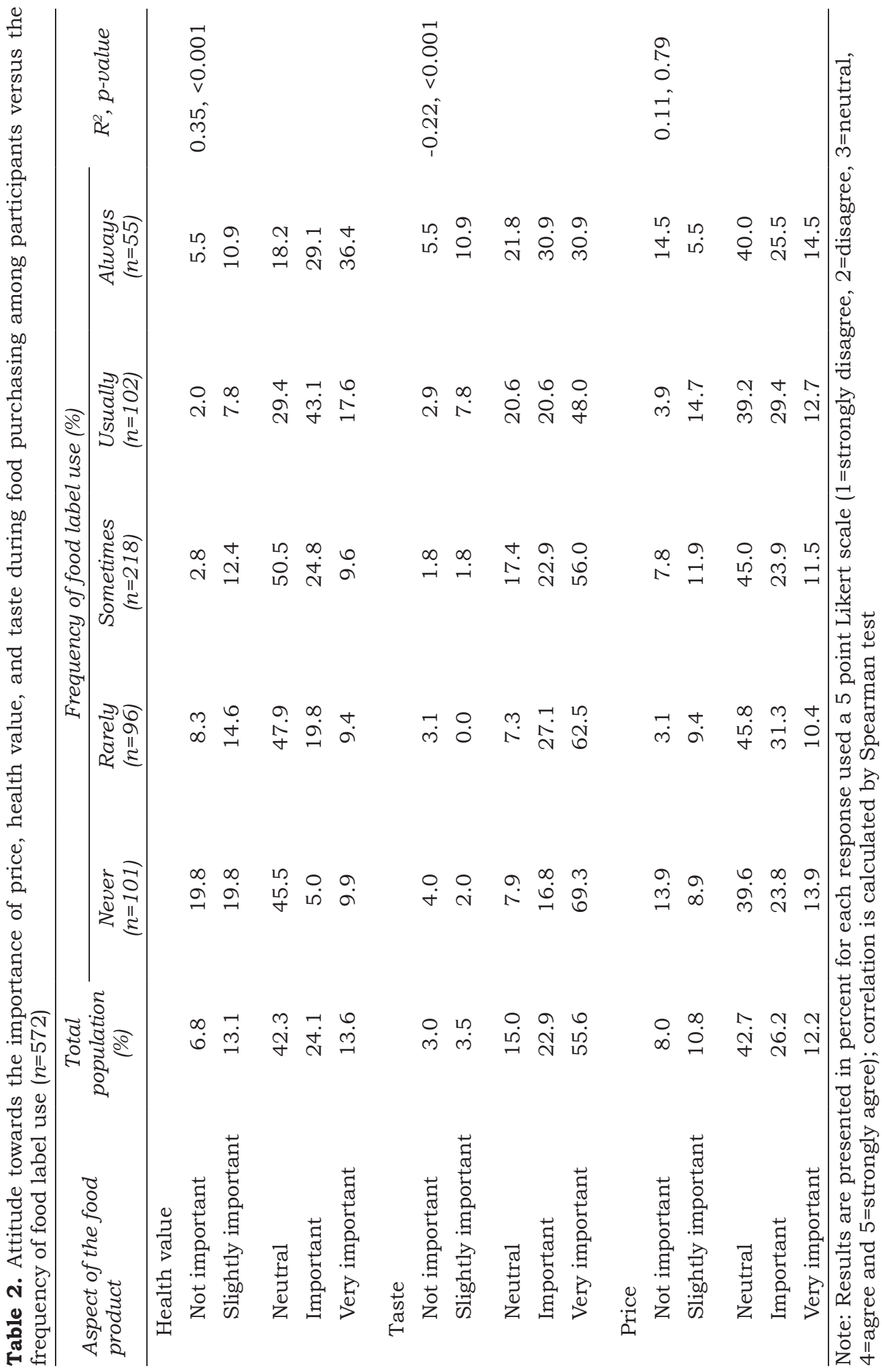


Barriers towards food labels use among Saudis

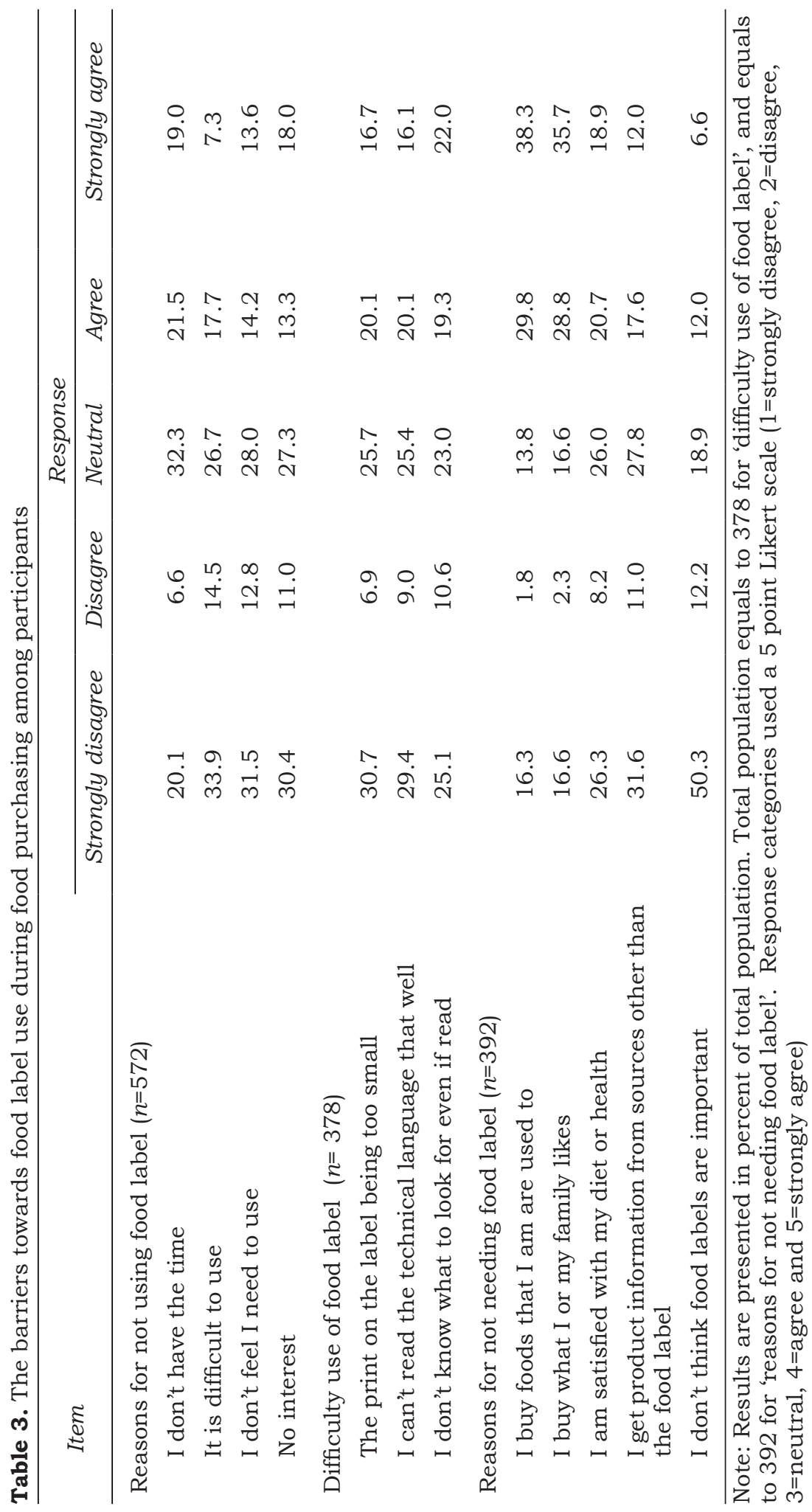




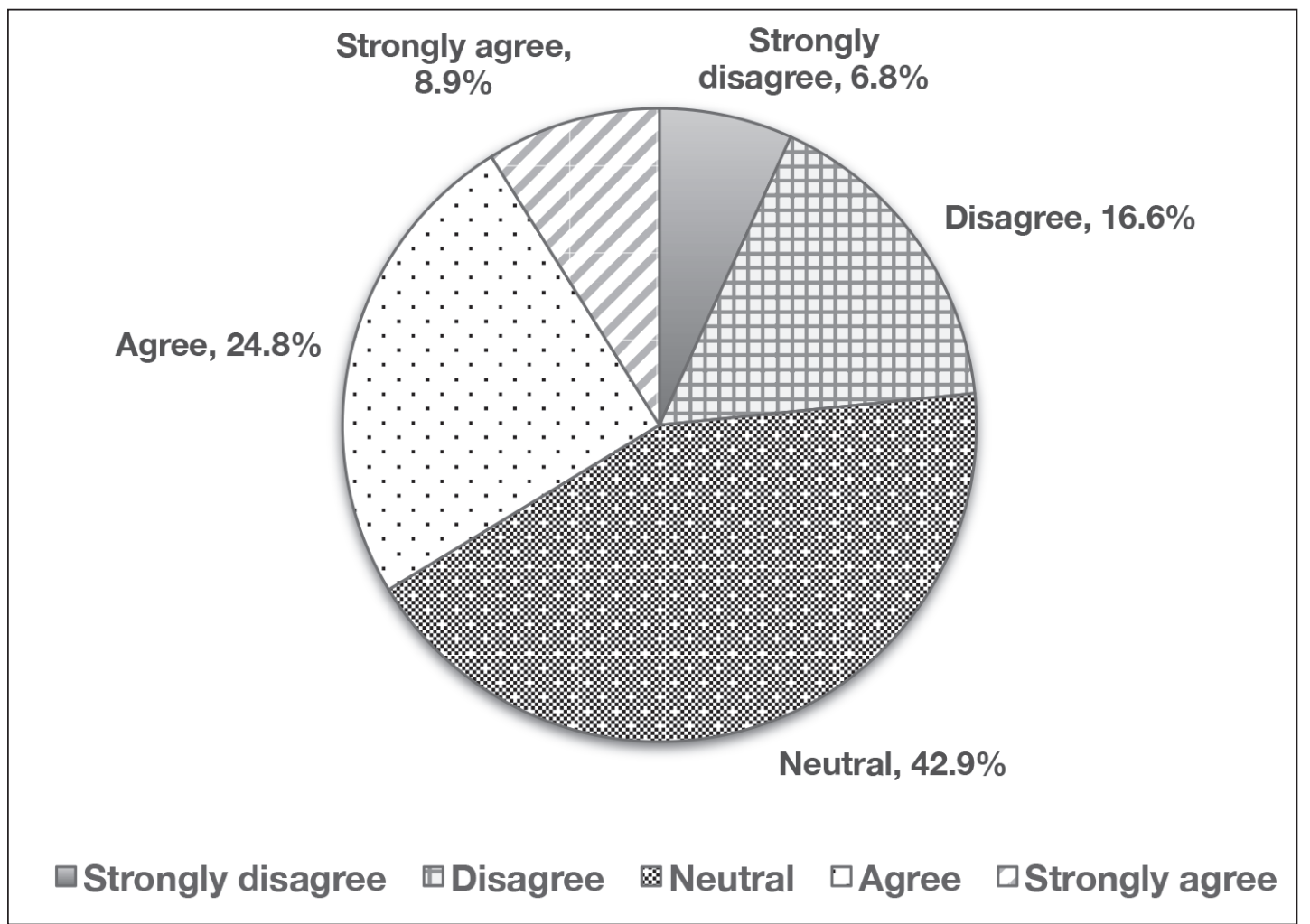

Figure 2. Distribution of respondent's attitude toward eating unhealthy food even in using food label $(n=471)$. Results are presented in percent of total population. Response categories used a 5 point Likert scale ( $1=$ strongly disagree, $2=$ disagree, $3=$ neutral, $4=$ agree and $5=$ strongly agree)

1). This scoring was significantly and positively associated with the frequency of food label use ( $p$-value $=0.04, R^{2}=0.21$ ) (Figure 1), indicating that the higher the scoring, the more frequent the use of food labels. Interestingly, more than three-quarters of the participants who had high knowledge $(75.6 \%)$ reported that they used food labels during purchasing.

\section{Attitude towards the importance of price, health value, and taste during food purchasing}

Results in Table 2 demonstrate that attitudes of participants towards health value and taste of food products were significantly correlated with the frequency of food label use during purchasing $(p=0.000)$. Correlations for attitudes towards these two aspects of food products were opposite as it was found to be positive for health value and negative for taste. The highest percentage for using food labels frequently (always) was observed among students who strongly agreed that the health value of a product is important (36.4\% for "always" versus $9.9 \%$ for "never"). While in the case of taste, students who strongly agreed that this aspect is important during purchasing, showed the lowest percentage for the frequency of "always" in food label use $(30.9 \%$ always versus $69.3 \%$ never).

Correlation was stronger with health value compared to taste $\left(R^{2}=0.35\right.$ and $R^{2}=-0.02$, respectively). No significant correlation was obtained between price and food label use. 


\section{Barriers towards food label use during purchasing}

As displayed in Table 3, about $41.0 \%$ of participants totally agreed or agreed that lack of time was the main reason for not using food label information during purchasing; followed by no interest $(31.3 \%)$, no need $(27.8 \%)$ and difficult to use $(24.8 \%)$. Among the 378 participants who stated that food label is difficult to use, $41.3 \%$ of them confirmed that they did not know what to look for, even if they used it. In addition, small prints and technical language were both identified as barriers for not using food labels by similar percentages $(36.8 \%$ and $36.2 \%$, respectively). The reasons given for not needing to use food labels included being used to certain food products $(68.1 \%)$ or buying favourite products, and what families preferred (64.5\%). However, $62.5 \%$ of them stated that food label is important, despite their belief that there is no need to use it (Table 3). Interestingly, $33.7 \%$ of participants confirmed that they would still purchase unhealthy foods even if they used the food labels during purchasing (Figure 2).

\section{DISCUSSION}

This study was designed to assess the frequency of using food labels during food purchasing among Saudi female university students and to evaluate their nutrition knowledge, as well as the common barriers that hinder their use of food labels. In fact, the SFDA (2018) issued regulations for mandatory food labelling, including enforcing the display of calorie information in restaurants and coffee shops (SFDA, 2018a). Such policies are aimed at promoting public health awareness within the frames of Saudi Arabia's vision 2030 and WHO guidelines by enabling Saudi consumers to choose healthy foods to reduce nutrition-related diseases (SFDA, 2018b). Thus, food label could be a consumer's dietary guideline, which influences them to make healthier food choices (Anastasiou et al., 2019).
Because of these great efforts advanced by SFDA, the assessment of Saudi consumers' use of food labels is urgently needed. Thus, the findings of the present research are relevant as they provide insights into Saudi consumers' awareness as revealed by the frequency of food label use and barriers hindering it.

This study showed that the frequency of food label use among female students was not high. The finding highlighted that only $27.4 \%$ of the participants used food labels, either "always" or "usually" when purchasing foods. The above finding is consistent with previous studies which suggest that the majority of participants only use food labels sometimes when buying food products (Bazhan, Mirghotbi \& Amiri, 2015; Nurliyana, Norazmir \& Khairil Anuar, 2011; Song et al., 2015). In contrast, Samson (2012) and Basarir \& Sherif (2012) concluded that participants who had a higher tendency of using food labels tended to pick products by themselves. While in the present study, less than a quarter $(24.5 \%)$ of the participants was responsible for food purchasing at home.

In addition, a positive and significant association between food label use and nutrition knowledge level among participants $(p=0.004)$ was found. The findings of this study revealed that $75.6 \%$ of students who had high nutrition knowledge level used food labels. This could indicate that nutrition knowledge is a promoter for food label use. Previous studies have confirmed similar findings where participants with higher knowledge were more likely to use food labels compared with those with low knowledge (Bazhan et al., 2015; BarreiroHurlé, Gracia \& de-Magistris, 2010; Norazlanshah et al., 2013). However, interestingly, this is contrary to a study conducted by Nurliyana et al. (2011) who stated that no significant association was obtained between the level of nutrition knowledge and the use of food labels. A plausible explanation is that 
besides nutrition knowledge, attitudes towards some other aspects of food products may influence food label use by consumers during purchasing. Indeed, the evidence from this study indicated that the more important the health value of the product, the more frequent is the use of food label. In contrast, when interest in taste increases, then there is a corresponding decrease in the use of food label. Moreover, this study found no association between food label use and the importance of price in the studied population. When purchasing foods, taste is the most important aspect among students $(78.5 \%)$ compared to price $(38.4 \%)$ and health value of the product $(37.7 \%)$, which is consistent with the students agreeing to purchase unhealthy foods despite what they have read on the food labels (33.7\%). These findings are supported by several studies, which stated that consumers grant taste the priority when purchasing food products (Jacobs, De Beer \& Larney, 2010; Zaidi \& Muhammad, 2012; Ababio, Adi \& Amoah, 2012; Van der Merwe, Bosma \& Ellis, 2014). Goodman et al. (2011) found that consumers were likely to give more attention to taste than nutritional information, which is in good agreement with the results of the present study.

However, besides factors that might promote food label use, there are a number of causes that impede it. The present study revealed that $40.9 \%$ of the students reported that the lack of time was the main reason for not using food labels. Other reasons were no interest, no need, and difficult to use, respectively. This might show that the majority of the students do not have the time to use food labels when purchasing and they assume that there is no need to waste time in using food labels because they know what to buy. In addition, Raseberry et al. (2007), Jacobs et al. (2010) and Barreiro et al. (2010) previously reported that shortage of time was the most common reason for not using food labels. Other authors predicted that the most common reason for not using food labels among female students might be time restriction due to studying that can use up most of their time (Nurliyana et al., 2011; Blitstein \& Evans, 2006). The present findings suggested that the causes for 'no need to use food label' were because students were buying products that they or their family liked or the foods that they were used to. This could be due to the observation that for the majority of students, it was their families who were responsible for food purchasing at home $(68.5 \%)$.

This study used a valid questionnaire and a substantial sample size $(n=572)$, representative of the five Health Colleges. However, due to the convenient sampling technique and the specific study population, these results cannot be generalised and may not reflect the attitudes of other Saudi population groups. Thus, further investigation including non-Health College students are needed to obtain a comprehensive analysis on the use of food labels. It is also essential to highlight the epidemic growth of diet-related diseases such as obesity, diabetes and cardiovascular disease in the Kingdom of Saudi Arabia and the importance of managing them is considered to be one of the major public health issues. In order to reduce the incidence rate of diet-related diseases in long-term, the promotion of food label use, which acts as a preventive tool in offering information about nutritional value as a guidance for healthier dietary behaviours, can help consumers to improve their food purchasing behaviours.

\section{CONCLUSION}

This study demonstrated that the frequency of food label use during purchasing among Health College students at PNU was low. Nutrition knowledge and the importance of healthy foods seem to be a promoting factor to 
food label use, while taste and lack of time were considerable barriers. Hence, emphasis on increasing the awareness towards health through nutrition education and/or individual counselling is needed to meet the expected results of SFDA's policies among the Saudi population. A plausible action would be a joining effort of Saudi stakeholders such as SFDA and the Ministry of Education to develop a policy to mainstream nutrition basics in all school curricula, as food knowledge is a predictor for increased use of food labels. As such, consumer awareness is a determinant that can be used to increase food label use, which will lead to healthier dietary options. And consequently, this will help reduce the prevalence of nutrition-related problems in the long term. On the other hand, food labelling should be revised to make it easier to read and be understood by the consumers.

\section{Acknowledgements}

This research was funded by the Deanship of Scientific Research at Princess Nourah bint Abdulrahman University through the Fast-track Research Funding Programme.

\section{Authors' contributions}

All authors provided substantial contribution in conception and design, or analysis and interpretation of data. They also work together in drafting the article or revising it critically for important intellectual content. Final review and approval of the version to be published was done by each of the authors.

\section{Conflict of interest}

The authors have no conflict of interest to be declared.

\section{References}

Ababio PF, Adi DD \& Amoah M (2012). Evaluating the awareness and importance of food labeling information among consumers in the Kumasi metropolis of Ghana. Food Control J 26(2):571574.

Al-Alyani $H$, Al-Turki $H A$, Al-Essa ON, Alani FM \& Sadat-Ali M (2018). Vitamin D deficiency in Saudi Arabians: a reality or simply hype: A meta-analysis (2008-2015). J Family Community Med 25(1):1-4.
Al-Assaf AH (2007). Anemia and iron intake of adult Saudis in Riyadh City-Saudi Arabia. Pak $J$ Nutr 6(4):355-358.

Al-Kandari D \& Jukes DJ (2012). The food control system in Saudi Arabia Centralizing food control activities. Food Control 28(1):33-46. https://doi.org/10.1016/j. foodcont.2012.03.030

Al-Kandari D \& Jukes DJ (2009). A situation analysis of the food control systems in Arab Gulf Cooperation Council (GCC) countries. Food Control 20(12):1112-1118. https://doi. org/10.1016/j.foodcont.2009.02.012

Anastasiou K, Miller M \& Dickinson K (2019). The relationship between food label use and dietary intake in adults: A systematic review. Appetite 138:280-291. https://doi:10.1016/j. appet.2019.03.025

Bakr SA \& Ayinde OL (2013). Awareness of GM food proliferation in Saudi Arabia: a case study of Makkah city. J Assoc Arab Univ Basic Appl Sci 13(1):8-13. https://doi.org/10.1016/j. jaubas.2012.09.003

Barreiro-Hurlé J, Gracia A \& de-Magistris T (2010). Does nutrition information on food products lead to healthier food choices? Food Policy $J$ 35(3):221-229.

Basarir A \& Sherif S (2012). Consumers awareness of food labeling: a case study of United Arab Emirates. Afr J Agric Res 7(28):4021-4028. http://www.academicjournals.org/AJAR DOI: 10.5897/AJAR12.1098

Bazhan M, Mirghotbi M \& Amiri Z (2015). Food labels: An analysis of the consumers' reasons for non-use. J Paramed Sci 6(1). https://doi. org/ 10.22037/jps.v6i1.8034

Blitstein JL \& Evans WD (2006). Use of nutrition facts panels among adults who make household food purchasing decisions. J Nutr Edu Behav 38(6):360-364.

FDA (2014). 2014 FDA Health and Diet Survey. Center for Food Safety and Applied Nutrition, Food and Drug Administration. From https://www.fda. gov/downloads / Food/foodscienceresearch/ consumerbehaviorresearch/UCM497251.pdf [Retrieved January 28 2019]

FDA (2018). Guide for older adults on using the nutrition facts label. Food and Drug Administration. From https://www.fda. gov/food/nutrition-education-resourcesmaterials / guide-older-adults-using-nutritionfacts-label [Retrieved July 31 2018]. 
Goodman S, Hammond D, Pillo-Blocka DF, Glanville $T$ \& Jenkins $R$ (2011). Use of nutritional information in Canada: national trends between 2004 and 2008. J Nutr Edu Behav 43(5):356-365.

IHME (2013). In: Saudi Health Interview Survey (SHIS). From http://www.healthdata.org/ ksa/projects/saudi-health-interview-survey [Retrieved October 10 2018].

Jacobs SA, De Beer H \& Larney M (2010). Adult consumers' understanding and use of information on food labels: a study among consumers living in the Potchefstroom and Klerksdorp regions, South Africa. Public Health Nutr 14(3):510-522. https://doi.org/10.1017/ S1368980010002430

Kamel S \& Al Otaibi H (2018). Trans-fats declaration, awareness and consumption in Saudi Arabia. Curr Res Nutr Food Sci 6(3). http:/ /dx.doi.org/10.12944/CRNFSJ.6.3.17

Kliemann N, Wardle J, Johnson F \& Croker H (2016). Reliability and validity of a revised version of the General Nutrition Knowledge Questionnaire. Eur J Clin Nutr 70(10):1174-1180.

Kristal AR, Levy L, Patterson RE, Li SS \& White $E$ (1998). Trends in food label use associated with new nutrition labeling regulations. Am J Public Health 88(8):1212-1215. https://doi. org/10.2105/AJPH.88.8.1212

Lewis JE, Arheart KL, Leblanc WG, Fleming LE, Lee DJ, Davila EP, Cabán-Martinez AJ, Dietz NA, McCollister KE, Bandiera FC \& Clark Jr JD (2009). Food label use and awareness of nutritional information and recommendations among persons with chronic disease. Am J Clin Nutr 90(5):1351-1357. https://doi:10.3945/ ajcn.2009.27684

Likert R (1932). A Technique for the measurement of attitudes. Archiv Fur Psychol 140:1-55.

Miller LMS \& Cassady DL (2015). The effects of nutrition knowledge on food label use. A review of the literature. Appetite 92:207-16. https:// doi.org/10.1016/j.appet.2015.05.029

Mokdad A (2016). Global non-communicable disease prevention: building on success by addressing an emerging health need in developing countries. J Health Spec 4(2):92. https: / / doi.org/ 10.4103/1658-600X.179820

Norazlanshah H, Muhammad I, Hasmira MD, Mashita M, Norfazlila MR \& Fazlyla NMF (2013). The use of nutrition label on food purchasing decision among university students in Kuantan, Malaysia. Health Environ J 4(1):1-10.

Nurliyana G, Norazmir MN \& Khairil Anuar MI (2011). Knowledge, attitude and practices of university students regarding the use of nutritional information and food labels. Asian J Clin Nutr 3(3):79-91.
Rasberry CN, Chaney BH, Housman JM, Misra R \& Miller PJ (2007). Determinants of nutrition label use among college students. Am J Health Edu 38(2):76-82. https://doi.org/10.1080/19 325037.2007.10598947

Sachithananthan V (2017). A study on the consumer awareness of food additives in packaged food and their effects on health in Abha region, Saudi Arabia. J Food Technol Pres 1(3):14-27.

Samson G (2012). Awareness of food labeling and use of the information in purchasing prepackaged food products among consumers in Ilala Municipality Dar Es-Salaam, Muhimbili. Master degree dissertation, University of Health and Allied Sciences.

SFDA (2018a). Healthy food strategy. Saudi Food and Drug Authority. From https://www.sfda. gov.sa/ar / awareness / Documents / SFDAhealthyfoodstrategy.pdf [Retrieved March 27 2019]

SFDA (2018b) In: Food labelling regulation. Saudi Food and Drug Authority. From https:// www.sfda. gov.sa/ar/food/news/Pages/f5-82018a1.aspx [Retrieved March 27 2019].

Song J, Huang J, Chen Y, Zhu Y, Li H, Wen Y, Yuan H \& Liang Y (2015). The understanding, attitude and use of nutrition label among consumers (China). Nutr Hosp 31(6):2703-2710. https:// doi.org/10.3305/nh.2015.31.6.8791

Van der Merwe, D, Bosma M \& Ellis S (2014). Consumers' opinions and use of food labels: results from an urban-rural hybrid area in South Africa. Food Res Inter 63:100-107.

Washi S (2001). Nutritional aspects of food labeling in Saudi Arabia. Ahfad J 18(2):17.

Williams EJ (2011). Nutritional Labeling. PhD dissertation. Honors Scholar Theses. University of Connecticut. https://opencommons. uconn.edu/srhonors_theses/176 [Retrieved September 24 2018]

WHO (2018). Non-communicable diseases country profiles 2018. World Health Organization. From https://www.who.int/nmh/publications/ncdprofiles-2018/en/ [Retrieved September 24 2018].

Zaidi S \& Muhammad B (2012). Awareness of Pakistani consumers towards nutritional labeling on product packaging in terms of buying behavior. Inter $J$ Business Social Sci 3:97-103. 